\title{
Effective Method for Decreasing Detection Limit of Dopant Concentration in Semiconductor Using Dual SDD Analysis System.
}

\author{
K. Fukunaga ${ }^{1}$, N. Endo ${ }^{1}$, M. Suzuki ${ }^{2}$ and Y. Kondo ${ }^{1}$ \\ 1. JEOL Ltd., 3-1-2 Musashino, Akishima, Tokyo, JAPAN. \\ 2. Thermo Fischer Scientific Japan, 3-9 Moriya-cho, Kanagawa-ku, Yokohama, JAPAN.
}

An energy dispersive spectrometer (EDS) analysis system using a Si drift detector (SDD) can perform a highly sensitive elemental analysis due to its flexibilities of detector shape and size and high speed processing. In addition, the use of multiple SDD sensors can dramatically enlarge the effective area of the detector, which should shorten the measurement period while increasing detection sensitivity. Up to now, transmission electron microscopy (TEM)-EDS has not been greatly used in the analysis of elements in semiconductor doping. This is because the limit of detection (LOD) by $\mathrm{Si}(\mathrm{Li})-\mathrm{EDS}$ is of the order of 1500-2000 ppm, which is a level of performance insufficient for dopant analysis in semiconductor industry. There has consequently been a strong desire to determine just how small an amount of elements can be detected (detection limit) using an analysis system with two SDDs. Theoretical estimation of LOD is determined with competition between the net counts for dopant element and the fluctuation of background tail of Si peak at the dopant peak energy [1]. When we measure the net counts of dopant element is three times larger than the fluctuation (sigma) of the background, it confirms the presence of the dopant with $99.7 \%$ certainty. Thus, we define a dopant concentration $\left(C_{\text {dopant }}\right)$ at LOD as

$$
C_{\text {dopant }}=\frac{3 k}{\sqrt{I_{n e t} \times P / B}} \ldots \text { (1) }
$$

,where the $I_{\text {net }}$ is net count of $\mathrm{Si}-\mathrm{K}$, the $P / B$ is ratio of net count of $\mathrm{Si}(P)$ and background count at energy of As lines $(B)$, and $k$ is $\mathrm{K}$ factor for lines of dopant. The previous works, we reported that the detection limit of dopant in Si was measured to be $30 \mathrm{ppm}$ using As K line at $200 \mathrm{kV}$ [2] for almost one hour acquisition. The equation (1) indicates that LOD decreases with increasing $\mathrm{I}_{\text {net }}$. LOD is proportional to $1 / \mathrm{I}_{\text {net }} \cdot \mathrm{I}_{\text {net }}$ is defined as follows

$$
I_{n e t} \propto Q_{k} \times W \ldots(2)
$$

, where the $\boldsymbol{Q}_{\boldsymbol{k}}$ is ionization cross section [3] and $\boldsymbol{W}$ is fluorescent yield. The $\boldsymbol{Q}_{\boldsymbol{k}}$ is inversely proportional to acceleration voltage of electron. While, $\boldsymbol{W}$ is independent on the acceleration voltage, because the fluorescence of X-ray is only related to after ionization of atoms, which is independent on incident electron energy. Therefore, it is valid to use lower acceleration voltage for decreasing LOD.

We also check the beam damage of Si sample at 100 and $200 \mathrm{kV}$. Figure 1 shows the transition of count rate of Si K $\alpha$, when the stationary beam is irradiated onto the sample. The count rate (which might be proportional to the thickness of the sample) at $100 \mathrm{kV}$ goes down slowly. On the other hand, count rate at $200 \mathrm{kV}$ goes down quickly to be around 0.1 . This caused by beam drilling of the sample, and the hole was made from top through bottom of the sample within around 50 second at $200 \mathrm{kV}$. The both measurements at 100 and $200 \mathrm{kV}$ were done under probe current $\left(\mathrm{I}_{\mathrm{p}}\right)=1 \mathrm{nA}$, probe size $\left(D_{p}\right)=0.7 \mathrm{~nm}$.

We used an As-doped Si wafer as a sample. The depth profile of As concentration in the Si wafer has been verified by secondary ion mass spectrometry (SIMS). We made a cross sectional lamella sample for TEM observation using an ion milling (Ion Slicer EM-09100IS, JEOL). The thickness of the TEM sample is estimated to be $130 \mathrm{~nm}$ judging from the count rate of X-ray and probe current $(2.5 \mathrm{nA})$ used by Faraday cage. We measured several data sets of EDS spectrum imaging at $200 \mathrm{kV}$ and $100 \mathrm{kV}$, using a FETEM (JEM-2800 JEOL) equipped with two SDD detectors. The concentration profiles were extracted and converted from the data set with quantitative analysis systems (NSS 3, Thermo Fisher Scientific and Analysis station, JEOL).

Figure 2 shows the X-ray spectra measured at $200 \mathrm{kV}$ and $100 \mathrm{kV}$ in point analysis mode. The 
acquisition time of each was 200 second. The intensity at $100 \mathrm{kV}$ is higher than that at $200 \mathrm{kV}$ throughout the energy range. The intensity of $\mathrm{Si} \mathrm{K} \alpha$, background at $\mathrm{As} \mathrm{K} \alpha, \mathrm{P} / \mathrm{B}$ ratio and estimated LOD are shown in Table 1 . Count of $\mathrm{Si} \mathrm{K \alpha}$ at $100 \mathrm{kV}$ is larger than that at $200 \mathrm{kV}$. Although the background of As $\mathrm{K} \alpha$ and $\mathrm{P} / \mathrm{B}$ ratio at $100 \mathrm{kV}$ are worse than at $200 \mathrm{kV}$, LOD at $100 \mathrm{kV}$ is better than at $200 \mathrm{kV}$. As you see the result of sample damage dependence, we can increase a measurement time only when we used $100 \mathrm{kV}$ in practical analysis. By measurement at lower accelerating voltage, increased $\mathrm{I}_{\mathrm{Si}}$ and destruction of the sample by electron beam is prevented, resulting in lower detection limit for the same sample.

\section{References:}

[1] TO. Ziebold, Anal. Chem. 39 (8) (1967), p. 858.

[2] K. Fukunaga, et al, Microscopy \& Microanalysis 21 (S3) (2015), p. 823.

[3] R.F. Egerton, "Electron Energy-Loss Spectroscopy in the Electron Microscope", 3rd edition, p. 197.

(a)

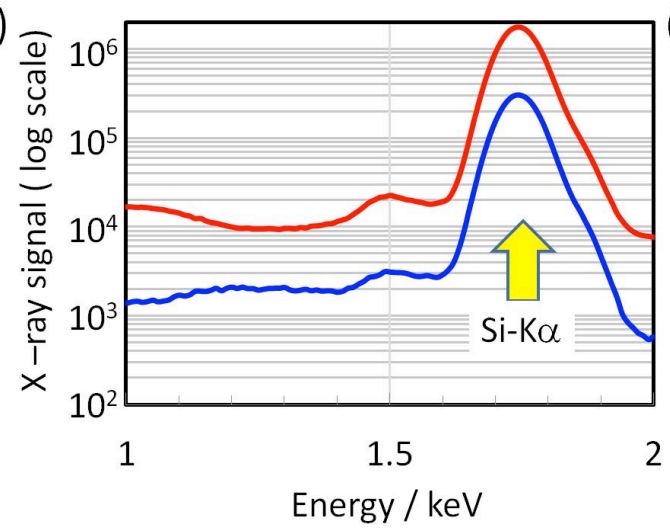

(b)

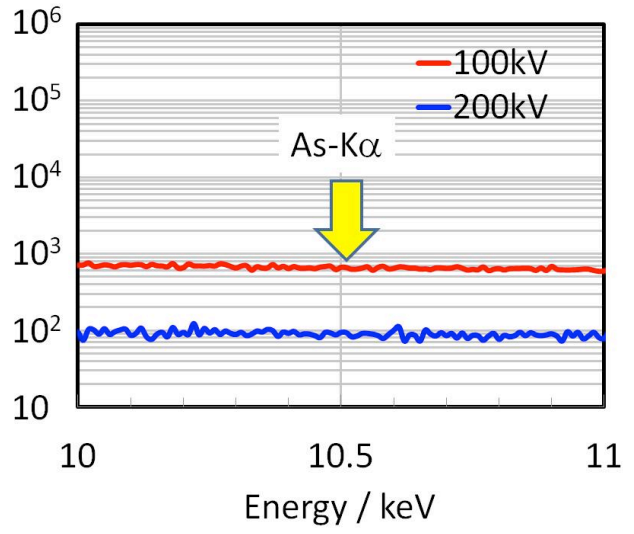

Figure 1. EDS spectra from the pure Si substrate region (a) Si-K, (b) As-K. As-K line is not shown in the spectrum because of taking data from Si substrate.

Table 1. The intensity of $\mathrm{Si} \mathrm{K} \alpha$, background at $\mathrm{As} \mathrm{K} \alpha, \mathrm{P} / \mathrm{B}$ ratio and estimated LOD

\begin{tabular}{|c|c|c|c|c|}
\hline Acc. Voltage & $\mathrm{I}_{\mathrm{Si}}$ at Si-K (P) & $\begin{array}{c}\text { Back ground } \\
\text { intensity at As K }\end{array}$ & P/B & LOD \\
\hline $100 \mathrm{kV}$ & $1.5 \times 10^{7}$ & $1.25 \times 10^{4}$ & $1.23 \times 10^{3}$ & $22 \mathrm{ppm}$ \\
\hline $200 \mathrm{kV}$ & $2.6 \times 10^{6}$ & $1.7 \times 10^{3}$ & $1.56 \times 10^{3}$ & $46 \mathrm{ppm}$ \\
\hline $\begin{array}{c}\text { Ratio } \\
100 \mathrm{kV} / 200 \mathrm{kV}\end{array}$ & 5.8 & 7.4 & 0.79 & \\
\hline
\end{tabular}

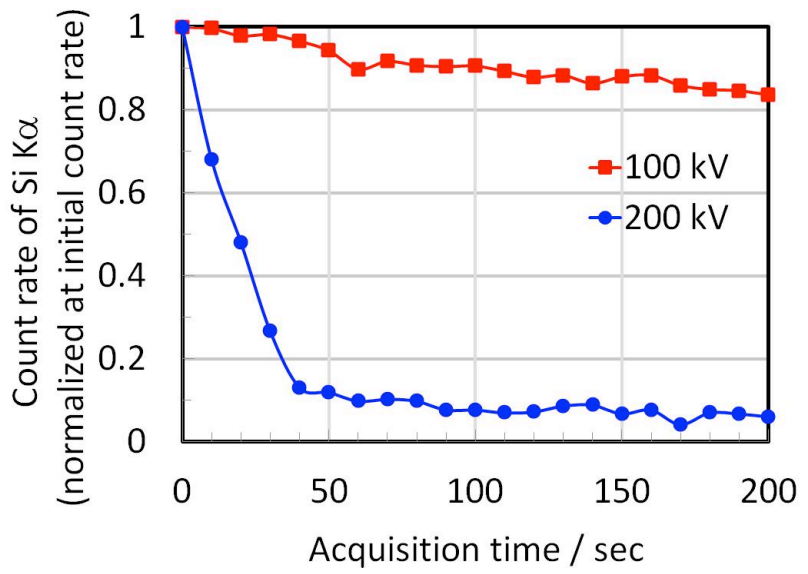

Figure 2. Changes of count rate of $\mathrm{Si} \mathrm{Ka}$ at 100 and $200 \mathrm{kV}$. Beam current was $2.5 \mathrm{nA}$ and sample thickness was estimated to be $130 \mathrm{~nm}$. 